\title{
Vocal Fold Vibration Characteristics during SOVTE using a Vibration Simulator and Digital Kymography
}

\author{
Ji Sung Kim ${ }^{a}$, Seong Hee Choi ${ }^{b}$, Kyungjae Lee ${ }^{b}$, Chul-Hee Choi ${ }^{b}$, Soo-Geun Wang, ${ }^{c}$ Dong-Wook Lee ${ }^{\mathrm{d}}$ \\ ${ }^{a}$ Department of Otorhinolaryngology, Chungbuk National University Hospital, Cheongju, Korea \\ ${ }^{b}$ Department of Audiology \& Speech-Language Pathology, Daegu Catholic University, Gyeongsan, Korea \\ 'Department of Otolaryngology, School of Medicine, Pusan National University, Pusan, Korea \\ ${ }^{d}$ Department of Otorhinolaryngology-Head and Neck Surgery, Chungbuk National University College of Medicine, Cheongju, Korea
}

\author{
Correspondence: Seong Hee Choi, $\mathrm{PhD}$ \\ Department of Audiology and Speech-Language \\ Pathology, Institute of Biomimetic Sensory Control, \\ and Catholic Hearing Voice Speech Center, Daegu \\ Catholic University, 13-13 Hayang-ro, Hayang-eup, \\ Gyeongsan 38430, Korea \\ Tel: +82-53-850-2542 \\ Fax: +82-53-359-6780 \\ E-mail: shgrace@cu.ac.kr
}

Received: September 7, 2021

Revised: November 26, 2021

Accepted: November 26, 2021

The research has been supported by the Ministry of Education of the Republic of Korea and the National Research Foundation of Korea (NRF2020S1A5A2a0145868).

\begin{abstract}
Objectives: The purpose of this study is to investigate the characteristics of vocal fold vibration during sustained vowel $/ \mathrm{a} /$ phonation and various semi-occluded vocal tract exercise (SOVTEs) using a vibration simulator and digital kymography (DKG). Methods: A total of 12 normal young speakers ( 6 males, 6 females) aged 20-30 years participated in the study. They phonated a sustained /a/ vowel and performed SOVTE. The vocal fold vibration characteristics were measured according to the number of vibration sources (single vs. double), and vocal tract occlusion degree using a vibration simulator and DKG. Glottal gap quotient (GQ, \%), speed quotient (SQ \%) and amplitude (pixel) were estimated quantitatively from the DKG image. Results: The results showed that significantly higher GQ $(p=.000)$ and SQ $(p=.000)$ were observed in the humming and bilabial fricative $/ \beta /$ compared to open vowels. The amplitude was significantly higher in the open vowel /a/ than in humming $(p=.018)$ and bilabial fricative $/ \beta /(p=.003)$. Also, when comparing the vocal fold vibration parameters according to vibration type (single source: straw phonation vs. double source: straw phonation with water), the double source presented a significantly higher $\mathrm{GQ}(p=.000)$ as well as SQ $(p=.008)$ in comparison with a single source. Conclusion: SOVTE showed a glottal gap that is different from the opened vowel /a/. It also had a longer opening of the vocal fold and a smaller amplitude than the vowel. This suggests that SOVTE may be helpful for facilitating vocal fold vibration and good voice quality in clinical practice. The current study can be meaningful in providing theoretical and clinical evidence for SOVTE.
\end{abstract}

Keywords: SOVTE, 2D DKG, Vibration simulator, Vocal fold vibration 반폐쇄성도운동(semi-occluded vocal tract exercise, SOVTE)은 성도의 앞이나 뒤의 일부를 폐쇄하여 발성하는 것이다(Titze, 2006). SOVTE는 직업적 음성사용자와 전문음성사용자의 음성훈련뿐만 아니라 과기능적 음성장애와 과소기능적 음성장애, 퇴행성 질환으 로 인한 신경학적 음성장애 등과 같은 병리적인 음성장애의 치료에 효과적으로 사용되어져 왔다(Chae, Choi, Choi, \& Lee, 2019; Chae, Lee, \& Choi, 2019; Kim, Choi, Choi, \& Lee, 2019; Kim \& Lee, 2020; Kim, Lee, Choi, \& Choi, 2017). 또한, 최근에는 직업적 음성사용자 의 비대면 음성치료에도 효과적인 방법으로 사용될 수 있음이 보 고되었다(Kim \& Choi, 2021).
SOVTE는 모음 [i], 입술 트릴, 양순 마찰음, 입으로 손 가리기, 반 모음 [y], 혀를 내밀고 입술 트릴과 혀 트릴을 동시에 실시하는 라즈 베리(raspberries), 컵 발성, 성대기능훈련의 [knoll]이나 공명음성 치료의 비성자음 $[\mathrm{m}, \mathrm{n}]$, 엑센트 기법의 유성마찰음과 같이 단순히 성도의 모양을 변형시키는 방법부터 유리나 실리콘 튜브, 플라스틱 빨대나 마스크와 같은 도구나 물을 이용하는 방법까지 매우 다양 하다(Titze, 2006). 대표적인 SOVTE의 종류에는 허밍, 입술 또는 혀 트릴 발성, 양순 마찰음, 튜브 또는 빨대발성 등이 있으며, 성도에 서 진동하는 진동원의 수에 따라 단일진동원(허밍, 튜브 또는 빨대 발성)과 이중진동원(물에 튜브 또는 빨대 넣어 발성 또는 입술 트릴 
또는 혀 트릴 발성)으로 나눌 수 있다. 단일진동원은 F0 (fundamental frequency, F0)와 F1 (first formant frequency, F1)의 차이가 크지 않아 관성 리액턴스가 증가하여 발성을 쉽게 만드는 효과가 있고, 이중진동원은 $\mathrm{F} 0$ 가 변하고 단일진동원에 비해 F0와 F1의 차이가 커 관성 리액턴스가 작아 이로 인해 발성이 쉬워지는 효과는 적지 만, 성문 사이의 압력 변화로 인해 성도와 성대에서의 마사지 효과 를 가진다(Andrade et al., 2014).

SOVTE는 물리법칙인 임피던스(impedance)를 기반으로 설명된 다. 임피던스는 에너지의 흐름에 대한 방해나 저항을 의미하는 것 으로 세부적으로는 에너지를 저장하고 진동수(frequency)에 의존 하는 리액턴스(reactance)와 에너지를 소멸시키고 진동수와 관련 이 없는 레지턴스(resistance)로 나뉜다. 리액턴스는 다시 자가 진동 (self-sustained oscillation)을 억제하는 유연성 리액턴스(compliance reactance)와 자가 진동을 촉진하는 관성 리액턴스(inertive reactance)로 구분한다(Choi, Choi, \& Lee, 2015). 음향관성(acoustic inertive reactance) 혹은 음향 임피던스(acoustic impedance)라 고도 하는 이 관성 리액턴스에 의해 SOVTE는 설명된다. 음성산출 에서 성도의 앞인 입술의 반폐쇄는 흡기와 호기의 순환에 의해 산 출되어야 할 호기류의 산출을 방해하고, 이로 인해 증가된 성문상 부의 구강 압력은 발성 시 저항으로 작용한다. 이 같은 저항 에너지 는 사라지는 것이 아니라 자가 진동을 촉진하는 관성 리액턴스에 의해 저장되어 성대의 효율적인 진동을 촉진한다(Kang et al., 2019). 다시 말해, 반폐쇄로 인한 높은 구강 압력은 성도에 저항으로 작용 하여 성대진동을 방해한다. 하지만, 성대의 진동이 시작되기만 하면 관성 리액턴스에 의해 저장된 에너지가 성대진동에 사용되기 때문 에 발성을 개시하고 유지하기 위한 최소발성역치(phonation threshold pressure, PTP)를 낮추고 최대유량감소율(maximum flow declination rate)을 증가시켜 음성의 강도가 증가되는 효율적인 발성이 촉진되는 것이다. 또한, SOVTE는 인간의 음성산출을 설명하는 음 원-필터이론이 아니라 반폐쇄로 인해 높아진 구강 압력의 공기역학 적 에너지가 성대로 되돌아가 음향학적 에너지로 전환되어 안면의 진동감을 발생시키는 감각 피드백으로서 음성산출에 관여한다는 비선형적 비선형 음원-필터이론으로 설명된다(Titze, 2001, 2006).

성도의 반폐쇄는 성대와 성도의 위치(location)와 모양(shape)을 변화시키며, 이에 따라 호흡, 발성, 공명의 음성산출 메커니즘 역시 일반적인 발성과 다르게 나타난다. 성도의 앞인 입술의 반폐쇄로 인해 높아진 구강 압력은 성대 쪽으로 돌아가는 역압(back pressure)을 발생시킨다. 이로 인해서 후두의 수직적 위치는 낮아지고, 하인두는 확장되며 연구개가 거상된 상태가 된다(Dargin, DeLaunay, \& Searl, 2016; Guzman, Laukkanen et al., 2013; Guzman,
Castro, Testart, Muñoz, \& Gerhard, 2013; Ogawa et al., 2013). 반폐 쇄 된 조건에서 발성이나 음도변화 시, 측윤상피열근과 윤상갑상근 에 비해 갑상피열근의 활동이 증가되어 최소발성역치압력(PTP)이 낮아져 보다 적은 공기역학적 에너지로 발성을 개시하는 반면, 성대 의 진동이 더 길게 유지된다(Laukkanen, Titze, Hoffman, \& Finnegan, 2008). 또한, 역압이 증가할수록 성문하압은 증가하고 성문 사 이 압력은 감소되며 최대유량감소율(maximum-flow declination rate)이 증가하여 음성의 강도를 증가시키는 공기역학적 특징이 나 타난다(Guzman, Higueras et al., 2013). 일반적인 모음 발성과 비교 했을 때는 SOVTE 시 성문하압과 성문 사이 압력이 더 높게 나타 나며, 전기성문파형검사(electroglotography, EGG)에서는 반폐쇄 시 성문하압의 증가로 인해 성대접촉률(contact quotient)이 증가되 는 양상을 보인다(Guzman et al., 2015, 2016; Ogawa et al., 2014). 성 도의 길이는 성문의 저항에 영향을 미칠 수 있는 또 다른 요소로서, $3.0 \mathrm{~mm}$ 보다 좁은 직경의 경우에서 성도의 길이가 연장되면 F1이 감소되어 성도를 좁히는 것과 동일하게 관성 리액턴스 효과가 나타 날 수 있다(Mills, Rivedal, DeMorett, Maples, \& Jiang, 2018; Titze, 2020).

성대진동의 직접적 관찰은 음성에 관한 가장 직접적인 정보를 얻 을 수 있는 방법이다. 하지만, 비강이나 구강을 통해 성대진동을 살 펴보는 후두스트로보스코피와 같은 일반적인 방법은 입술과 연인 두밸브가 동시에 폐쇄되는 SOVTE 시 성대진동을 관찰하는데 적 절하지 못하다(Cordeiro, Montagnoli, Nemr, Menezes, \& Tsuji, 2012; Granqvist et al., 2015; Vlot et al., 2017). 성대의 진동을 측정 하는 또 다른 방법으로 $\mathrm{EGG}$ 를 적용할 수 있지만, $\mathrm{EGG}$ 는 실제 성 문의 개방 정도가 아니라 양측 성대의 접촉률만을 나타낸다. 또한, 성대의 비접촉보다는 접촉에 대한 정보를 더 정확히 제공하며 성대 접촉면과 접촉된 길이의 정도에 따라 차이가 있을 수 있다는 제한 점이 있다(Wang, 2013). 반면, 다양한 소재와 모형을 사용하여 성 대의 물리적 생리학적 특성을 살펴볼 수 있는 성대 시뮬레이션은 후두내시경이나 EGG와 같은 제한이 없기 때문에 SOVTE 시 성대 진동을 살펴보는데 유용하게 사용될 수 있다(Barney, 1995; Tao, Jiang, \& Zhang, 2006).

카이모그래피(kymography)는 성대진동의 기능적 측면인 성대 진동 양상에 대한 정보를 얻을 수 있는 영상학적 성대진동 평가방 법이다. 카이모그래피는 고정된 수평선에서 스캔 라인별로 시공간 적으로 측정하고, 여러 주기에 걸쳐 성대의 진동을 평가할 수 있기 때문에 SOVTE 시 좌, 우측 성대의 주기 별 운동의 직접적이고 객 관적인 정량화가 가능하다(Kendall, Browning, \& Skovlund, 2005; Švec, Šram, \& Schutte, 2007). 이에 본 연구는 음성의 음향학적 에 
너지를 기반으로 하며, 입력된 음성이 시뮬레이터에 전달되면 인공 성대에서 진동이 생성되게 하는 진동시뮬레이터를 이용하여 SOVTE 시 성대진동을 구현하고자 한다. 또한, 이를 초고속 비디오 후두내시경(High speed video laryngoscope)을 이용하는 라인 스 캐닝 디지털 카이모그래피(line scanning digital kymography)를 사용하여 살펴봄으로써 SOVTE의 이론적, 임상적 근거를 마련하 고자 한다. 본 연구의 연구주제는 다음과 같다.

첫째, 성도의 좁힘(개방모음, 허밍, 유성양순마찰음)에 따른 성대 진동에 차이가 있는가?

둘째, 단일진동원(빨대발성)과 이중진동원(물저항빨대발성)의 성대진동에 차이가 있는가?

\section{연구방법}

\section{연구대상}

본 연구의 대상자는 20-32세 성인 12 명이다. 남성과 여성 각각 6 명으로 평균 연령 $22.48 \pm 4.82$ 세이며 연구 참여에 동의하였다. 본 연구에 포함된 대상자의 선정기준은 (1) 만 19세 이상 성인으로 최 근 상기도 감염 및 후두 질환으로 진단을 받지 않은 자, (2) 흡연을 하지 않은 자, (3) 성대에 기질적인 병변이 없는 자, (4) 발성 시 성문 주변 수축과 같은 기능적인 문제가 없는 자, (5) 갑상선 질환 또는 폐 질환을 동반하지 않는 자, (6)음성장애 평가 및 치료 경력 5년 이 상인 1 급 언어재활사 2 명에 의해 $\mathrm{GRBAS}$ 를 이용한 청지각적 평가 에서 G0으로 평가된 자, (7) VHI-10에서 12점 미만인 자였다. 12점 미만의 기준은 K-VHI-10의 정상 수준 절단점에 관한 연구가 없어 국외연구의 기준을 적용하였다(Arffa, Krishna, Gartner-Schmidt, \& Rosen, 2012). 본 연구는 대구가톨릭대학교 생명윤리위원회의 승 인을 받아 진행하였다(CUIRB-2019-0062).

\section{연구도구}

\section{진동시뮬레이터}

SOVTE 시 성대진동을 분석하기 위하여 Figure 1과 같이 실리콘 블록 모델을 이용한 진동시뮬레이터(유메디컬, 부산)를 사용하였 다. 진동시뮬레이터는 음원이 음원입력기(sound source)인 마이크 (SM48, SHURE, Germany)를 통해 증폭기(amplifier)인 오디오 시 스템(MQ-L420, Samsung, Korea)에 전달되며 증폭기에서 시뮬레 이터로 전달되어 진동이 생성된다. 시뮬레이터는 두 개의 우퍼 스 피커가 알루미늄 프레임에 세로로 고정되고 금속막대와 연결된다. 금속막대 중간 부분은 실리콘 인공성대를 고정하기 위한 아크릴 기판이 설치되어 있다. 진동시뮬레이터의 우퍼 스피커에 연결된 금 속막대를 통해 아크릴판으로 진동이 전달되면 좌우 인공성대가 각 각 우퍼 스피커로부터 독립적으로 진동을 전달받는다. 인공성대의 중앙부의 각 모서리는 인공성대의 파동을 극대화하기 위해 반대쪽 모서리보다 가능한 얇게 구성하였으며, 성대의 경도와 최대한 비슷 한 연성을 가지도록 하였다. 진동시뮬레이터는 카메라시스템을 통 해 다시 다기능 후두성능검사 시스템에 연결하였다. 본 연구에 사 용된 진동시뮬레이터(Figure 1)는 Bae (2017)와 동일한 것으로 본 연구의 실험 목적에 맞게 수정되었다. 해당 진동시뮬레이터는 실제 성대진동과 동일한 진동주기를 가지며, 음성파형과 전기성문파형 과도 동일한 주파수의 파형을 나타내어 그 신뢰성이 검증되었다.

\section{다기능 후두성능검사 시스템}

하이스피드 비디오카메라 영상의 촬영을 위하여 Kang 등(2017) 이 개발한 다기능 후두성능검사 시스템(multifunctional examination system; USC-700MF, U-Medical, Korea)을 이용하였다. 다기 능 후두성능검사 시스템은 저장된 하이스피드 영상을 이용하여 디 지털 카이모그래피와 평면 스캔 디지털 카이모그래피 분석이 가능

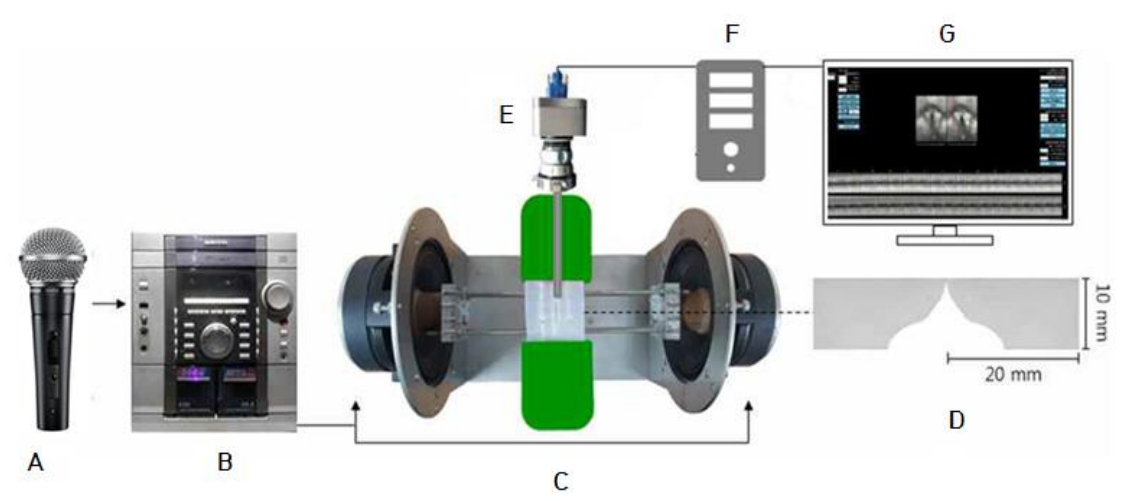

Figure 1. Modified Vibration simulator using silicon block model.

A=Microphone; $B=A m p ; C=$ Vibration simulator; $D=$ Section of silicon block; $E=$ High speed video laryngoscope; $F=$ Desktop; $G=$ Monitor. 
하며, 디지털 카이모그래피는 실시간으로 멀티라인 평가할 수 있 다. 또한 초고속 후두 비디오내시경 영상을 기반으로 초고속 후두 비디오내시경 영상, 평면 스캔 비디오 카이모그래피, 멀티 라인 디 지털 카이모그래피를 동시에 분석할 수 있다(Figure 2).

\section{연구절차}

\section{자료수집}

연구 대상자는 진동시뮬레이터와 연결된 마이 크 앞에서 마이크 와 $5 \mathrm{~cm}$ 의 간격을 두고, 편안한 음도와 강도에서 연구자의 모델링 에 따라 개모음//발성과 SOVTE를 10 초간 실시하였다. 실험을 위

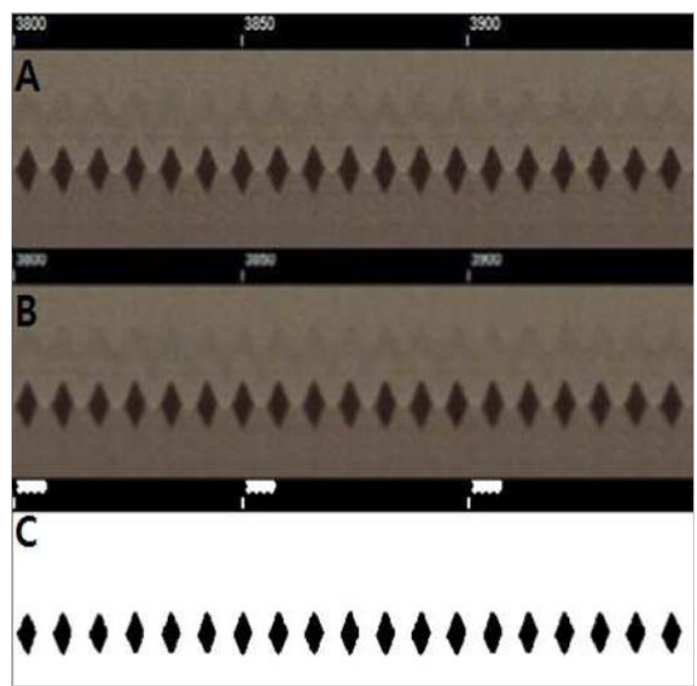

Figure 2. Image processing for quantitative analysis.

$A=$ Stable section 150 msec of raw image; $B=$ after smooth process of $A$; $\mathrm{C}=$ after binary process of $\mathrm{B}$.
해 실시한 SOVTE의 종류는 허밍, 유성양순마찰음 $/ \beta /$, 빨대발성 (빨대 너비 $4 \mathrm{~mm} \times$ 빨대 길이 $18 \mathrm{~cm}$ ), 물저항빨대발성(빨대 너비 4 $\mathrm{mm} \times$ 빨대 길이 $18 \mathrm{~cm} \times$ 물 깊이 $4 \mathrm{~cm}$, 빨대 너비 $4 \mathrm{~mm} \times$ 빨대 길 이 $18 \mathrm{~cm} \times$ 물 $7 \mathrm{~cm}$ )이었다. 실험에 앞서 연구자는 SOVTE를 발성 유형별로 모델링하였으며, 대상자들은 올바른 방법으로 SOVTE를 수행하고 과제수행동안 음도의 변화가 $\pm 20 \mathrm{~Hz}$ 범위 내에 유지되 도록 각 SOVTE를 10 분씩 2회 연습하였다. 과제수행의 순서는 대 상자마다 무작위순으로 수행하도록 하였다. 물저항빨대발성 시 물 거품 소리가 진동시뮬레이터에서 인식되지 않음을 확인하였으며, 빨대에 눈금을 그어 물의 깊이를 통제하였다. 대상자의 수행에 따 라 산출된 음성은 증폭기(amplifier)인 오디오 시스템(MQ-L420, Samsung, Korea)을 거쳐 진동시뮬레이터로 전달된다. 이후 진동시 뮬레이터는 입력된 음향학적 정보를 운동에너지로 변환하여 진동 을 생성하는데, 진동시뮬레이터의 진동은 다기능 후두성능검사기 와 연결된 후두내시경(10 mm, 0도, $8701 \mathrm{AG}$, Storz, Germany)을 통해 하이 스피드 모드로 녹화하였다.

\section{자료분석}

SOVTE 시 진동 시물레이터의 진동은 다기능 후두성능검사 시 스템에 의해 하이 스피드 모드로 녹화되며, $240 \times 320$ 픽셀의 해상 도로 $1,350 \mathrm{fps}$ (frame per seconds)가 저장된다. 이후 다기능 후두 성능검사 시스템의 라인 스캐닝(Figure 3A, green line)을 통해 라 인 스캔 디지털 카이모그래피 이미지를 획득하였다. 이와 같은 후 처리를 통해 얻은 10 seconds의 디지털 카이모그래피 이미지 중 성 문의 형태가 일정하고 성대의 진동주기가 안정적인 발성 개시 1 초 후 $150 \mathrm{msec}$ 의 구간을 분석 구간으로 선정하였다. 또한, 성대진동
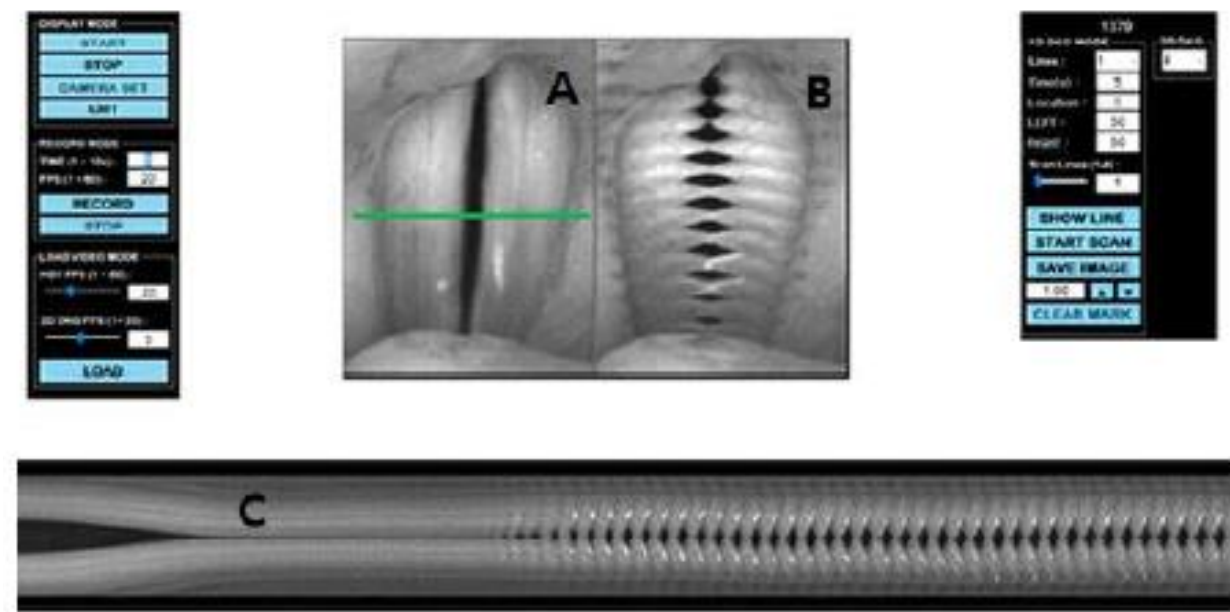

Figure 3. Screen of Multi-function laryngeal evaluation system.

$\mathrm{A}=$ High speed video videoendoscopic image; $\mathrm{B}=$ Two-dimensional digital kymography; $\mathrm{C}=$ Digital kymography 
의 정량적 측정을 위해 이 중 다시 3 개의 안정된 주기를 선정 및 분 석하였으며, 측정치를 평균값을 사용하였다.

\section{예비연구}

본 연구에서 진동시뮬레이터의 타당도 검증을 위해 정상 남성 모음 발성 시 성대를 초고속 비디오 후두내시경으로 촬영하고 이 와 동일하게 내시경을 구강에 넣은 상태로 마이크 앞에서 발성 하 였다. 이후 촬영된 성대와 시뮬레이터의 영상을 라인 스캔 디지털 카이모그래피로 변환하여 비교한 결과 두 방법에서 동일하게 11 개 의 진동주기를 관찰할 수 있었다. 이 중 3 개의 주기를 선정하여 성 문 개방지수(Open quotient, OQ), 성문 폐쇄지수(Closed quotient, $\mathrm{CQ})$, 성대접촉속도(Speed quotient, SQ)를 측정한 결과, 모음 발성 과 진동시뮬레이터의 CQ가 $54.68 \%, 54.04 \%, \mathrm{OQ}$ 는 $45.32 \%, 45.96 \%$, $\mathrm{SQ}$ 는 $99.17 \%, 98.11 \%$ 로 거의 동일하게 나타났으며, 이를 통해 Bae (2017)에서 검증된 진동시뮬레이터의 타당성을 재확인하였다. 또 한, 정상 음성 남성을 대상으로 비강연성후두내시경 $(3 \mathrm{~mm}, \mathrm{MA}-$ CHIDA ENDOSCOPE, Japan)을 사용하여 개방모음/아/와SOVTE 시 성대진동을 관찰하였으며, 이와 동일하게 마이크 앞에서도 실시 하여 진동시뮬레이터로 시뮬레이팅 하였다. 비강후두내시경은 이 비인후과 전문의에 의해 실시되었다. 비강연성후두내시경 시 성대 진동영상과 진동시뮬레이터의 인공성대진동 영상을 라인 스캔 디 지털 카이모그래피로 후처리한 후 비교한 결과, 비강후두내시경을 통해 관찰한 실제 성대진동과 진동시뮬레이터를 이용한 라인 스캔 디지털 카이모그래피가 시지각적으로 거의 유사한 성대진동을 나 타내었다(Figure 4).

SOVTE 수행 시 구강으로 경성후두내시경을 통해 성대의 진동 을 관찰할 수 없기 때문에 비강통로를 이용하여 관찰해야 한다. 비 강후두내시경은 코를 통해 연인두를 지나 성대진동을 관찰하므로 비도(nasal airway)가 일부 개방되는 허밍을 제외한 나머지 SOVTE 에서는 연인두 밸브의 완전한 폐쇄는 불가능한 조건이 된다. 때문 에 비강후두내시경을 통해 촬영한 SOVTE 시 성대진동과 실제
SOVTE의 진동시뮬레이터의 라인 스캔 디지털 카이모그래피는 약 간의 차이가 나타날 수 있다. 예비연구에서 연인두 밸브가 약간 개 방된 불완전한 폐쇄 조건의 허밍 경우, 비강후두내시경의 라인 스 캔 디지털 카이모그래피와 진동시뮬레이터의 라인 스캔 디지털 카 이모그래피의 성문의 개방과 폐쇄 정도가 유사하게 나타났으나, 완 전한 연인두 폐쇄가 이루어지는 빨대발성에서는 비강후두내시경 과 진동시뮬레이터의 라인 스캔 디지털 카이모그래피는 약간 다르 게 나타났다. 빨대발성 시 비인두내시경을 통해 관찰한 성대진동에 비해 진동시뮬레이터의 라인 스캔 디지털 카이모그래피의 성대진 동 시 성문 상압이 증가하므로 주기의 폐쇄성은 감소하고 주기의 개방성이 더 증가되어 나타났다. 하지만, 성문의 형태에 있어 개방 모음에서는 대체적으로 마름모의 형태가, 빨대발성에서는 외측 경 계가 뾰족하지 않고 예리함이 감소한 둥근 형태가 비인두내시경과 진동시뮬레이터를 이용한 두 방법에서 모두 동일하게 나타났다. 허 밍의 성문형태도 이와 동일하게 외측 경계의 예리함이 감소한 것을 관찰할 수 있었으며 성문 안에 구슬이 든 것 같이 성문 내측의 성문 틈이 증가된 것을 볼 수 있다. 이를 통해, 개방모음, 허밍, 빨대발성 의 라인 스캔 디지털 카이모그래피에서 나타난 성문의 형태는 진 동시뮬레이터에서도 동일하게 구현됨을 확인할 수 있었고, 이를 통 해 진동시뮬레이터의 타당성을 재확인할 수 있었다. 하지만, 비강 을 이용하는 연성후두내시경은 작은 카메라 렌즈 사이즈로 인해 선명한 성대의 진동 이미지를 얻는데 한계가 있었으며, 피험자는 실 험동안 구토반사를 호소할 뿐만 아니라 비강을 통한 성대 촬영 이 후에도 비도에 불편감이 지속됨을 호소하였다. 이에 본 연구에서 는 본 실험에 앞서 정상인의 개방모음 발성 및 SOVTE의 발성이 비 강연성후두내시경과 진동시뮬레이터의 라인 스캔 디지털 카이모 그래피에서 유사한 성대진동 패턴을 확인함으로써 반폐쇄 시의 성 대의 진동 특성을 확인하기 위한 도구로 진동시뮬레이터의 타당도 를 확인할 수 있었다(Figure 4).
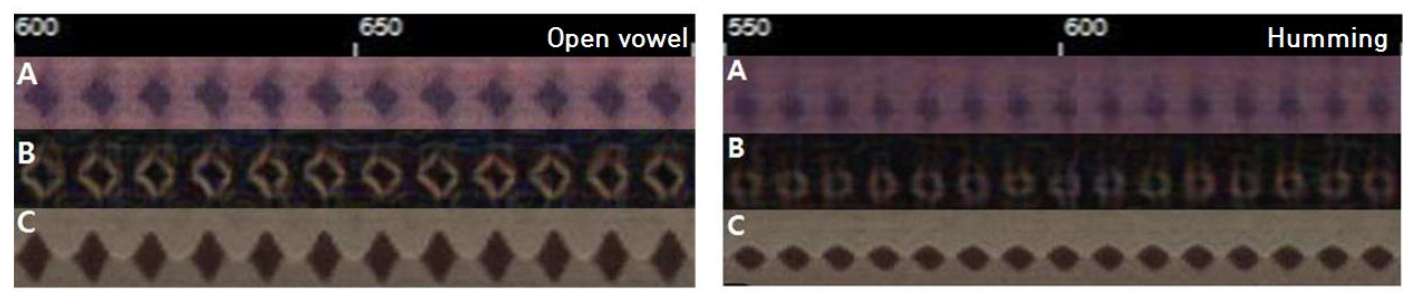

Figure 4. Line scanning digital kymography during open vowel and humming. $A=$ flexible laryngoscopy image; $B=$ modified image of flexible laryngoscopy; $C=$ vibration simulator laryngoscopy image. 


\section{음성측정}

\section{성대진동의 정량적 측정}

개방모음 / / / 와 SOVTE 시 성대진동의 정량적 측정을 위해 Park 등(2016)의 방법을 수정 및 보완하여 사용하였다. 다기능 후두성능 검사 시스템의 라인 스캔 디지털 카이모그래피 이미지에서 안정된 성대진동이 나타나는 3주기를 선정하고, Image J (NIH, Bethesda, $\mathrm{MD}$ )의 Smooth와 Binary 프로세스를 통해 이미지를 변환하였다 (Figure 2). 이후, Lohsceller, Eysholdt와 Dollinger (2008), Lohscheller, Toy, Rosanowski, Eysholdt와 Döllinger (2007), 그리고 Moukalled 등(2009)와 동일한 방법으로 성문의 꼭지점을 선정하고 Image J의 Measure Tool을 이용하여 성대의 진동을 측정하였다. Image J 측정된 값은 숫자로 나타나지만 단위는 제시되지 않는다. 이러 한 방법을 통해 Park (2015)의 방법을 수정 및 보완하여 개방모음/ ㄱ/와 SOVTE의 (1) 성문 틈비율(Glottal gap quotient), (2) 성대접 촉지수(Speed quotient), (3) 진폭(Vocal amplitude)을 측정하였다.

\section{성문틈 비율(Glottal gap Quotient, GQ)}

SOVTE의 종류에 따른 성문간격 차이를 비교하기 위해 Figure 5 과 같이 성문 간격의 길이(amplitude)를 측정하여 성문의 틈(glottal gap)을 성대의 진폭주기로 나누어 계산하였다. 계산공식은 Glottal gap Quotient (\%)= Glottal gap/Amplitude $\times 100$ 이다. GQ 가 클수록 성대진동 시 발생되는 성문 틈이 크다는 것을 의미한다. 성대접촉속도(Speed Quotient, SQ)

성대접촉속도는 Figure 5과 같이 성대의 한 진동주기 내에서 성 문 개방기(opening phase)와 폐쇄기(closing phase)의 속도를 나타 낸다. 성문이 개방되는 시간을 성문이 폐쇄되는 시간으로 나누어

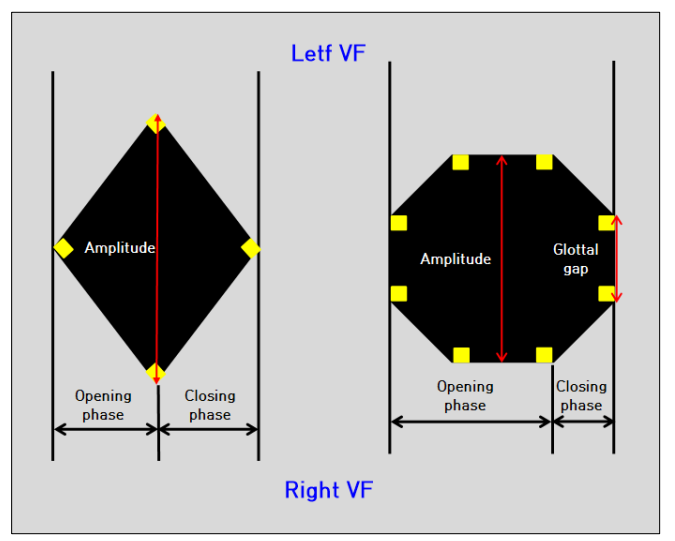

Figure 5. Quantitative measurement of open vowel /a/ and SOVTE. $A=$ Stable section 150 msec of raw image; $B=$ after smooth process of $A$; $\mathrm{C}=$ after binary process of $\mathrm{B} ; \mathrm{VF}=$ vocal fold.
계산하였다. 계산공식은 $\mathrm{SQ}=$ Opening phase/Closing phase이다. $\mathrm{SQ}$ 가 1 보다 크면 개방기가 더 길다는 것을 의미한다.

\section{진폭(Amplitude)}

SOVTE의 종류에 따른 진폭 차이를 비교하기 위해 Figure 5과 같이 좌우 성대의 가장 외측 경계 지점 사이의 거리(픽셀, pixel)를 측정하였다. 측정되는 값이 클수록 성대진동의 진폭이 크다는 것 의 의미한다.

\section{신뢰도 분석}

본 연구에서 실시한 정량적 분석의 신뢰도를 확인하기 위해 전 체 샘플 중 $20 \%$ 를 무작위로 추출하여 검사자 간 분석을 실시하였 다. 이를 위해 연구자 외에 음성장애 평가 및 치료 경력 5년 이상인 1 급 언어재활사 1 명이 분석 실시하였으며 그 결과, 연구자가 실시한 분석 결과와 성문틈 비율, 성대접촉속도, 진폭 모두 소수점 이하 제 외 시 $100 \%$ 였고, 소수점 첫 자리까지 계산 시 각각 $100 \%, 97.9 \%$, 98.75\%로 나타났다. 연구자는 신뢰도 검사를 위한 분석 전 측정방 법에 대한 예시와 설명 후 분석을 실시하였다.

\section{결과처리}

성도의 좁힘 정도에 따른 성대진동을 비교하기 위해 One-way Mixed Repeated Measures ANOVA (SPSS version 21.0)로 분석하 였다. 개방모음 / / /, 유성양순마찰음 / $\beta /$, 허밍을 피험자 내 요인 (within-subjects factor)으로 하여 각 집단의 성문틈 비율, 성대접 촉지수, 진폭을 비교하였다. 반복측정의 통계적 유의성을 위해 구 형성 검정(Mauchly's sphericity tests)을 실시하였으며, Mauchly의 구형성 검정에 의해 구형성 가정을 충족하는 경우에는 개체 내 효 과 검정을 사용하였다. 구형성 가정을 충족하지 않는 경우에는 Greenhouse-Geisser로 수정된 자유도와 F값을 사용하여 분석하 였다. 또한 개체 내 효과 검정 결과 통계적으로 유의미한 차이가 있 는 경우는 대비 검정을 실시하였다. SOVTE의 진동유형에 따른 성 대진동은 Paired $t$-test를 실시하였다. 본 연구의 통계적 유의수준 은.05수준에서 검정하였다.

\section{연구결과}

성도의 좁힘정도(개방모음 / / / 유성양순마찰음 / $\beta /$, 허밍)에 따 른 성대진동을 비교하기 위해 성문틈 비율 $(\mathrm{GQ})$, 성대접촉지수 (SQ), 진폭을 측정하고 비교하였다(Table 1). 먼저, 성문틈 비율에 서 개방 모음은 성문 틈이 없어 $0 \%$ 이었고, 허밍은 $32.67 \%$, 유성양 
Table 1. Comparison of vocal vibration according to vocal tract occlusion

\begin{tabular}{lccccc}
\hline & Open vowel /a/ & Bilabial fricative $/ \beta /$ & Humming & $F$ & $p$-value \\
\hline Glottal gap quotient & $0.00(.00)$ & $42.00(9.75)$ & $32.67(12.38)$ & 86.257 & $.000^{* * *}$ \\
Speed quotient & $1.11(.21)$ & $2.05(.50)$ & $2.11(.38)$ & 420.701 & $.000^{* * *}$ \\
Amplitude & $16.72(6.87)$ & $10.05(2.48)$ & $11.32(2.50)$ & 192.093 & $.000^{* * *}$ \\
\hline
\end{tabular}

Values are presented as mean (SD).

${ }^{* * *} p<.001$.

Table 2. Comparison of vocal fold vibration according to SOVTE vibration type

\begin{tabular}{lcccc}
\hline & Straw phonation & Straw phonation with water (depth 4cm) & $t$ & $p$-value \\
\hline Glottal gap quotient & $37.56(7.75)$ & $53.16(8.72)$ & -5.600 & $.000^{* * *}$ \\
Speed quotient & $1.87(3.3)$ & $2.88(8.7)$ & -3.241 & $.008^{* *}$ \\
Amplitude & $10.48(2.52)$ & $10.85(1.12)$ & -.445 & .665 \\
\hline
\end{tabular}

Values are presented as mean (SD).

${ }^{* *} p<.01,{ }^{* * *} p<.001$.

순마찰음 $/ \beta / 42 \%$ 로 통계적으로 세 유형 간 유의한 차이가 나타났 다 $(\mathrm{F}=86.257, p=.000)$. 대응별 비교를 실시한 결과, 개방모음은 허 밍, 유성양순마찰음 $/ \beta /$ 와 유의한 차이 $(p=.000)$ 를 보였으며, 유성 양순마찰음 $/ \beta /$ 와 허밍 $(p=.026)$ 에서도 유의한 차이가 나타났다. 성대접촉속도에서 개방 모음은 1.11 , 유성양순마찰음 $/ \beta /$ 는 2.05 , 허밍은 2.11로 통계적으로 유의한 차이가 나타났다 $(\mathrm{F}=420.701$, $p=.000)$. 대응별 비교를 실시한 결과, 개방모음은 허밍, 유성양순 마찰음 $/ \beta /$ 와 유의한 차이 $(p=.000)$ 를 보였으며, 유성양순마찰음 $/ \beta /$ 와 허밍 $(p=.692)$ 은 유의한 차이가 없었다. 진폭에서 개방 모음 의 평균은 16.72 , 유성양순마찰음 $/ \beta /$ 는 10.05 , 허밍은 11.32 로 통계 적으로 유의한 차이가 나타났다 $(\mathrm{F}=192.093, p=.000)$. 대응별 비 교를 실시한 결과, 개방모음은 허밍 $(p=.018$, 유성양순마찰음 $/ \beta /$ 와 유의한 차이 $(p=.003)$ 를 보였으며, 유성양순마찰음 $/ \beta /$ 와 허밍 $(p=.128)$ 은 유의한차이가 없었다.

단일진동원인 빨대발성과 이중진동원인 물저항빨대발성의 성대 진동을 비교하기 위해 성문틈 비율 $(\mathrm{GQ})$, 성대접촉속도(SQ), 진폭을 측정하고 비교하였다(Table 2). 성문틈 비율에서 빨대발성의 평균은 $37.56 \%$, 물저항빨대발성은 $53.16 \%$ 로 통계적으로 유의한 차이가 나 타났다 $(t=-5.600, p=.000)$. 성대접촉속도에서는 빨대발성이 1.87 , 물 저항빨대발성은 2.88 로 통계적으로 유의한차이가 있었다 $(t=-3.241$, $p=.008)$. 진폭에서는 빨대발성이 10.48 pixel, 물저항빨대발성 10.85 pixel로 나타났으며, 통계적으로 유의한차이는 나타나지 않았다.

\section{논의 및 결론}

본 연구는 SOVTE 시 성대진동의 특성을 알아보기 위해, 진동시
뮬레이터와 라인 스캔 디지털 카이모그래피를 이용하여 음성 문제 가 없는 20세 이상 정상 성인 12 명을 대상으로 성도의 좁힘 정도와 SOVTE 진동유형에 따른 성대진동을 비교하였다. 성대진동 변수 로 성문틈 비율과 성대접촉속도, 진폭을 측정하고 비교한 결과, 성 도의 좁힘이 있는 허밍과 유성양순마찰음이 개방 모음보다 성문틈 비율이 크고 성대접촉속도가 더 빨랐으며, 진폭은 더 작았다. 이는 좁힘 정도에 따른 성도의 저항의 크기 차이 때문일 것이다. SOVTE 진동유형에 따라서는 이중진동원인 물저항빨대발성이 단일진동 원인 빨대발성에 비해 성문틈 비율이 더 크고 성대접촉속도는 더 빠르게 나타났다. 이 역시 진동원 수에 의한 차이라기보다는 물로 인한 성도저항 증가로 인해 이중진동원인 물저항빨대발성이 더 큰 구강 압력과 역압이 생성되기 때문일 것이다. 이러한 차이는 성도 의 반폐쇄 시 발생되는 성도의 저항에 의한 것으로 SOVTE만의 독 특한 성대진동 특성이라 할 수 있겠다.

본 연구에서 나타난 SOVTE 시 발생되는 성문 틈은 SOVTE 시 성대가 약간 외전되어 진동한다는 외전가설을 지지하는 결과이다. Titze (2006)는 역압의 발생으로 SOVTE 시 성대가 약간 외전 된 상 태에서 진동한다는 성대 외전가설을 제시하였다. SOVTE에 관한 선행연구들 역시 SOVTE 시 성대 외전으로 인해 성대가 과도하게 충돌하지 않기 때문에 발성 시 성대진동 충격이 적어 발성 시 경제 성과 효율성이 증가된다고 보고하였다(Andrade et al., 2016; Dargin et al., 2016; Guzman, Higueras et al., 2013; Paes, Zambon, Yamasaki, Simberg, \& Behlau, 2013; Titze, 2001, 2006, 2018; Titze \& Laukkanen, 2007; Titze \& Story, 1997).

성대의 접촉속도는 후두 위치에 따른 성대점막의 경도(stiffness) 에 영향을 받는다. 후두의 위치가 상승하면 성대 점막의 경도가 증 
가되고 조이는(tight)듯 한 성대 내전이 발생된다(Shipp, 1987; Sundberg \& Nordstrom, 1976). 반대로, 후두의 위치가 낮아지면 성대 의 점막이 느슨하고 부드러워진다(Titze, 1993). 성대점막의 경도는 성대접촉속도에 영향을 미치는데, 일반적으로 성대점막의 경도가 증가되었을 때 성대의 개방기가 짧아져 성대접촉속도가 감소된다 (Berke \& Gerratt, 1993). 반대로 성대점막의 경도가 저하되면 성대 의 개방기는 길어지고, 성대접촉속도 역시 증가될 것이다. 성대접 촉속도의 증가는 성대진동 시 성문의 개방기가 폐쇄기에 비해 더 길다는 것으로 성대가 빨리 닫히고 천천히 열림을 의미한다. 성대 접촉속도의 증가는 성문 사이를 통과하여 지나가는 공기의 흐름을 순간적으로 빠르게 끊어줄 수 있어 보다 선명한 성대음(glottal sound)을 생성으로 이어진다(Choi, 1998). SOVTE 시 이와 같은 성 대진동이 나타나는 것은, 성도의 저항으로 인해 F0가 F1보다 낮아 져 성문 개방 시의 기류가 성문의 주기에서 폐쇄기를 억제하기 때 문이며, 이로 인해 모든 배음의 에너지가 더 크게 나타나 성대가 명 료한 소리를 낼 수 있도록 진동하며 그 결과 음질이 향상되게 되는 것이다(Story, Laukkanen, \& Titze, 2000). 이는 SOVTE를 이용한 치료가 음질을 향상시킨다는 선행연구와 일치하는 결과인 동시에 이에 대한 임상적, 이론적 근거를 제시한다(Kapsner-Smith, Hunter, Kirkham, Cox, \& Titze, 2015, Kim et al., 2017, Meerschman et al., 2019).

Kendall과 Leonard (2010)에 의하면 성대진동의 진폭(amplitude)은 성대조직의 유연성, 성문하압, 성대진동 시 내측 압착(medial compression)정도에 따라 결정된다. 성대 조직의 유연성이 증 가되면 성대를 지나는 기류에 의한 성대의 움직임이 더 쉽게 나타 나기 때문에 성대진동의 진폭이 증가된다. 성문하압이 증가하면 진 동의 진폭도 커지며, 반대로 성문하압이 감소되면 진폭도 작아진 다. 성문하압의 증가는 호기의 양을 늘리거나, 강한 성대의 내측 압 착에 의해 증가될 수 있다. 일반적으로 내측 압착이 증가하면 성문 을 지나는 기류의 저항이 증가하며, 이에 따른 저항을 극복하기 위 한 성문하압의 증가가 필요하다. 호기의 양을 증가시켜 큰 소리를 내면 성대의 진폭이 증가하고 음성강도 역시 증가한다. 호기의 증 가 없이 성대내측의 압착만을 증가시켜 발성하면 성문을 지나는 기 류의 저항이 증가하여 이에 따른 저항을 극복하기 위한 성문하압 은 증가하지만, 오히려 성대내근의 수축에 의해 진폭은 작아진다. 반대로 부드러운 발성(soft voice)은 성대조직을 지나는 호기류의 힘이 작아 성대의 진폭 역시 작게 나타난다. 앞서 기술한 진폭의 메 커니즘에 의하면, 성도의 반폐쇄 시 성대점막이 부드러운 상태가 되고 성문하압이 증가하기 때문에 성대의 진폭도 증가되어야 한다. 하지만, SOVTE 시는 성대는 약간 외전된 상태가 되어 성문하압이
증가되어도 높아진 하압이 성대의 접촉에 그대로 반영되지 못하기 때문에 성대가 강하게 접촉하지 못하며, 성대진동에 영향을 미치 는 호기류의 힘 역시작은 상태가 된다. 때문에, 본 연구에서 성대의 진폭이 개방모음에 비해 적게 나타난 것이다. 본 연구에서 SOVTE 시 성대진동의 진폭이 개방모음에 비해 작음에도 불구하고, 선행 연구에서는 SOVTE가 음성의 강도를 증가시킨다고 보고되어왔다. 이는, SOVTE 시 반폐쇄로 위한 구강의 높은 공기역학적 에너지가 성대로 돌아가 음향학적 에너지로 바뀌고, 발성에 있어 안면의 진 동감으로 관여하여 음성산출 시 공명의 증가로 인한 것일 것이다.

본 연구에서 나타난 SOVTE 시 성대진동의 특징은 SOVTE가 단 순히 성도의 앞인 입술을 좁히고 공명을 강화하는 이로운 성대진 동을 촉진한다는 것을 넘어, 근거기반중재(evidence-based practice)로서 병리적인 음성장애 환자의 음성치료나 전문 음성사용자 의 음성훈련에 대한 SOVTE의 근거를 제시한다는 점에서 큰 의의 를 가진다. 본 연구는 SOVTE 중 허밍, 양순마찰음, 빨대발성, 물저 항빨대발성 4 종류의 성대진동을 정량적으로 측정하고 비교하였 다. 후속연구에서는 다양한 SOVTE의 발성을 추가적으로 살펴보 는 것이 필요하겠으며 동물성대를 이용하거나 기류를 기반으로 하 는 시뮬레이터를 통해 SOVTE 시 성대의 진동에 대한 연구가 후속 될 필요가 있겠다.

\section{REFERENCES}

Andrade, P. A., Wistbacka, G., Larsson, H., Södersten, M., Hammarberg, B., Simberg, S., ... \& Granqvist, S. (2016). The flow and pressure relationships in different tubes commonly used for semi-occluded vocal tract exercises. Journal of Voice, 30(1), 36-41.

Andrade, P. A., Wood, G., Ratcliffe, P., Epstein, R., Pijper, A., \&Svec, J. G. (2014). Electroglottographic study of seven semi-occluded exercises: Lax Vox, straw, lip-trill, tongue-trill, humming, hand-over-mouth, and tonguetrill combined with hand-over-mouth. Journal of Voice, 28(5), 589-595.

Arffa, R. E., Krishna, P., Gartner-Schmidt, J., \& Rosen, C. A. (2012). Normative values for the voice handicap index-10. Journal of Voice, 26(4), 462465.

Bae, I. H. (2017). The efficacy of two-dimensional scanning digital kymography using vibration simulator in differentiation of diplophonia (Doctoral Dissertation). Busan University, Busan, Korea.

Barney, J. B. (1995). Looking inside for competitive advantage. Academy of Management Perspectives, 9(4), 49-61.

Berke, G. S., \& Gerratt, B. R. (1993). Laryngeal biomechanics: an overview of 
mucosal wave mechanics. Journal of Voice, 7(2), 123-128.

Chae, H. R., Choi, S. H., Choi, C. H., \& Lee, K. (2019). Effects of Lax Vox voice therapy on respiration and phonation in patients with Parkinson's disease. Communication Sciences \& Disorders, 24(3), 785-799.

Chae, H. R., Lee, D. W., \& Choi, S. H. (2019). Effects of semi-occluded vocal tract exercise in patients with functional aphonia. Journal of The Korean Society of Laryngology, Phoniatrics and Logopedics, 30(1), 48-52.

Choi, C. H., Choi, S. H., \& Lee, K. J. (2015). Speech science. Seoul: sigmapress.

Choi, H. S. (1998). Vocal Tract Resonance. Proceedings of The Korean Society of Laryngology, Phoniatrics and Logopedics, 201-207.

Cordeiro, G. F., Montagnoli, A. N., Nemr, N. K., Menezes, M. H. M., \& Tsuji, D. H. (2012). Comparative analysis of the closed quotient for lip and tongue trills in relation to the sustained vowel/ع. Journal of Voice, 26(1), e17-e22.

Dargin, T. C., DeLaunay, A., \& Searl, J. (2016). Semioccluded vocal tract exercises: changes in laryngeal and pharyngeal activity during stroboscopy. Journal of Voice, 30(3), 377-e1.

Guzman, M., Calvache, C., Romero, L., Muñoz, D., Olavarria, C., Madrid, S., ... \& Bortnem, C. (2015). Do different semi-occluded voice exercises affect vocal fold adduction differently in subjects diagnosed with hyperfunctional dysphonia?. Folia Phoniatrica et Logopaedica, 67(2), 68-75.

Guzmán, M., Castro, C., Madrid, S., Olavarria, C., Leiva, M., Muñoz, D., ... \& Laukkanen, A. M. (2016). Air pressure and contact quotient measures during different semioccluded postures in subjects with different voice conditions. Journal of Voice, 30(6), 759-e1.

Guzman, M., Castro, C., Testart, A., Muñoz, D., \& Gerhard, J. (2013b). Laryngeal and pharyngeal activity during semioccluded vocal tract postures in subjects diagnosed with hyperfunctional dysphonia. Journal of Voice, 27(6), 709-716.

Guzman, M., Higueras, D., Fincheira, C., Muñoz, D., Guajardo, C., \& Dowdall, J. (2013c). Immediate acoustic effects of straw phonation exercises in subjects with dysphonic voices. Logopedics Phoniatrics Vocology, $38(1), 35-45$.

Guzman, M., Laukkanen, A. M., Krupa, P., Horáček, J., Švec, J. G., \& Geneid, A. (2013a). Vocal tract and glottal function during and after vocal exercising with resonance tube and straw. Journal of Voice, 27(4), 523-e19.

Granqvist, S., Simberg, S., Hertegård, S., Holmqvist, S., Larsson, H., Lindestad, P. Å., ... \& Hammarberg, B. (2015). Resonance tube phonation in water: High-speed imaging, electroglottographic and oral pressure observations of vocal fold vibrations-a pilot study. Logopedics Phoniatrics Vocology,
40(3), 113-121.

Kang, D. H., Wang, S. G., Park, H. J., Lee, J. C., Jeon, G. R., Choi, I. S., ... \& Shin, B. J. (2017). Real-time simultaneous DKG and 2D DKG using highspeed digital camera. Journal of Voice, 31(2), 247-e1.

Kang, J., Xue, C., Chou, A., Scholp, A., Gong, T., Zhang, Y., ... \& Jiang, J. J. (2019). Comparing the exposure-response relationships of physiological and traditional vocal warm-ups on aerodynamic and acoustic parameters in untrained singers. Journal of Voice, 33(4), 420-428.

Kapsner-Smith, M. R., Hunter, E. J., Kirkham, K., Cox, K., \& Titze, I. R. (2015). A randomized controlled trial of two semi-occluded vocal tract voice therapy protocols. Journal of Speech, Language, and Hearing Research, 58(3), 535-549.

Kendall, K. A., Browning, M. M., \& Skovlund, S. M. (2005). Introduction to high-speed imaging of the larynx. Current Opinion in Otolaryngology \& Head and Neck Surgery, 13(3), 135-137.

Kendall, K. A., \& Leonard, R. J. (2010). Laryngeal evaluation: indirect laryngoscopy to high-speed digital imaging. Georg Thieme Verlag.

Kim, J. S., \& Choi, S. H. (2021). Effect of non-face-to-face voice therapy using the self-voice health care program for vocal fatigue. Communication Sciences \& Disorders, 26(2), 501-509.

Kim, J. S., Choi, S. H., Choi, C. H., \& Lee, D. W. (2019). Effect of voice therapy for persistent dysphonia following laryngeal microsurgery. Communication Sciences \& Disorders, 24(2), 525-534.

Kim, J. S., \& Lee, D. W. (2020). Effect of voice reinforcement method for treatment of vocal nodules: preliminary study. Journal of The Korean Society of Laryngology, Phoniatrics and Logopedics, 31(1), 13-18.

Kim, J. S., Lee, D. W., Choi, C. H., \& Choi, S. H. (2017). Effects of laryngeal massage and semi-occluded vocal tract exercises for patients with hyperfunctional dysphonia. Communication Sciences \& Disorders, 22(4), 806817.

Laukkanen, A. M., Titze, I. R., Hoffman, H., \& Finnegan, E. (2008). Effects of a semioccluded vocal tract on laryngeal muscle activity and glottal adduction in a single female subject. Folia Phoniatrica et Logopaedica, 60(6), 298-311.

Lohscheller, J., Eysholdt, U., Toy, H., \& Dollinger, M. (2008). Phonovibrography: mapping high-speed movies of vocal fold vibrations into 2-D diagrams for visualizing and analyzing the underlying laryngeal dynamics. IEEE Transactions on Medical Imaging, 27(3), 300-309.

Lohscheller, J., Toy, H., Rosanowski, F., Eysholdt, U., \& Döllinger, M. (2007). Clinically evaluated procedure for the reconstruction of vocal fold vibra- 
tions from endoscopic digital high-speed videos. Medical Image Analysis, 11(4), 400-413.

Mills, R. D., Rivedal, S., DeMorett, C., Maples, G., \& Jiang, J. J. (2018). Effects of straw phonation through tubes of varied lengths on sustained vowels in normal-voiced participants. Journal of Voice, 32(3), 386-e21.

Meerschman, I., Van Lierde, K., Ketels, J., Coppieters, C., Claeys, S., \& D’haeseleer, E. (2019). Effect of three semi-occluded vocal tract therapy programmes on the phonation of patients with dysphonia: lip trill, waterresistance therapy and straw phonation. International Journal of Language \& Communication Disorders, 54(1), 50-61.

Moukalled, H., Deliyski, D., Schwarz, R., \& Wang, S. (2009). Segmentation of laryngeal high-speed videoendoscopy in temporal domain using paired active contours. Models and Analysis of Vocal Emissions for Biomedical Applications, 6, 137-140.

Ogawa, M., Hosokawa, K., Yoshida, M., Yoshii, T., Shiromoto, O., \& Inohara, H. (2013). Immediate effectiveness of humming on the supraglottic compression in subjects with muscle tension dysphonia. Folia Phoniatrica et Logopaedica, 65(3), 123-128.

Ogawa, M., Hosokawa, K., Yoshida, M., Iwahashi, T., Hashimoto, M., \&Inohara, H. (2014). Immediate effects of humming on computed electroglottographic parameters in patients with muscle tension dysphonia. Journal of Voice, 28(6), 733-741.

Park, H. J. (2015). Development of vocal fold vibration parameters using area extraction algorithm of two dimensional scanning videokymography (Doctoral dissertation). Busan University, Busan, Korea.

Park, H. J., Cha, W., Kim, G. H., Jeon, G. R., Lee, B. J., Shin, B. J., ... \& Wang, S. G. (2016). Imaging and analysis of human vocal fold vibration using twodimensional (2D) scanning videokymography. Journal of Voice, 30(3), 345-353.

Paes, S. M., Zambon, F., Yamasaki, R., Simberg, S., \& Behlau, M. (2013). Immediate effects of the finnish resonance tube method on behavioral dysphonia. Journal of Voice, 27(6), 717-722.

Shipp, T. (1987). Vertical laryngeal position: research findings and application for singers. Journal of Voice, 1(3), 217-219.

Story, B. H., Laukkanen, A. M., \& Titze, I. R. (2000). Acoustic impedance of an artificially lengthened and constricted vocal tract. Journal of Voice, 14(4), 455-469.

Sundberg, J., \& Nordström, P. E. (1976). Raised and lowered larynx-the effect on vowel formant frequencies. Speech Transmission Laboratory Quarterly Progress and Status Report, 17(2-3), 035-039.

Švec, J. G., Šram, F., \& Schutte, H. K. (2007). Videokymography in voice disorders: what to look for?. Annals of Otology, Rhinology \& Laryngology, 116(3), 172-180.

Tao, C., Jiang, J. J., \& Zhang, Y. (2006). Simulation of vocal fold impact pressures with a self-oscillating finite-element model. The Journal of the Acoustical Society of America, 119(6), 3987-3994.

Titze, I. R. (1993). Raised versus lowered larynx singing. National Association of Teachers of Singing Journal, 50, 37.

Titze, I. R. (2001). Acoustic interpretation of resonant voice. Journal of Voice, 15(4), 519-528.

Titze, I. R. (2006). Voice training and therapy with a semi-occluded vocal tract: rationale and scientific underpinnings. Journal of Speech, Language, and Hearing Research, 49(2). 448-459.

Titze, I. R. (2018). Major benefits of semi-occluded vocal tract exercises. Journal of Singing, 74(3), 311-312.

Titze, I. R. (2020). Inertagrams for a variety of semi-occluded vocal tracts. Journal of Speech, Language, and Hearing Research, 63(8), 2589-2596.

Titze, I. R., \& Laukkanen, A. M. (2007). Can vocal economy in phonation be increased with an artificially lengthened vocal tract? A computer modeling study. Logopedics Phoniatrics Vocology, 32(4), 147-156.

Titze, I. R., \& Story, B. H. (1997). Acoustic interactions of the voice source with the lower vocal tract. The Journal of the Acoustical Society of America, 101(4), 2234-2243.

Vlot, C., Ogawa, M., Hosokawa, K., Iwahashi, T., Kato, C., \& Inohara, H. (2017). Investigation of the immediate effects of humming on vocal fold vibration irregularity using electroglottography and high-speed laryngoscopy in patients with organic voice disorders. Journal of Voice, 31(1), 4856.

Wang, S. G. (2013). Analysis of glottal vibration. Journal of the Korean Society of Phoniatrics and Logotedics, 24(1). 28-32. 


\section{국문초록}

\section{진동시뮬레이터와 디지털 카이모그래피를 이용한 반폐쇄성도운동 시 성대진동의 특성}

김지성 1 최성희 ${ }^{2} \cdot$ 이경재 ${ }^{2} \cdot$ 최철희 ${ }^{2} \cdot$ 왕수건 $^{3} \cdot$ 이동욱 $^{4}$

1충북대학교병원 이비인후과 음성치료실, ${ }^{2}$ 대구가톨릭대학교 언어청각치료학과, ${ }^{3}$ 부산대학교 의과대학 이비인후과, ${ }^{4}$ 충북대학교 의과대학 이비인후과

배경 및 목적: 반폐쇄성도운동은 직업적 음성사용자와 전문 음성사용자의 음성훈련뿐만 아니라 병리적인 음성장애의 치료에 효과적 으로 사용되어져 온 방법이다. 본 연구는 진동시뮬레이터와 디지털 카이모그래피(DKG)를 이용하여 SOVTE 시 성대진동의 특징을 살 펴보고 SOVTE의 이론적 임상적 근거를 마련하고자 한다. 방법: 연구 대상자는 20-30세 정상음성 성인 12명(남 6명, 여 6명)이다. 대상 자들은 개방모음/F/와 SOVTE를 수행하였다. 연구자는 성도의 좁힘 정도(개방모음/F/, 허밍, 유성양순마찰음 / $/$ )와 SOVTE의 진동 원 수(단일진동원: 빨대발성, 이중진동원: 물저항빨대발성)에 따른 성대진동 차이를 비교하기 위해 진동시뮬레이터 및 DKG를 사용하 여 성대의 진동을 정량적으로 측정하였다. 측정변수는 성문틈 비율(Glottal Quotient, \%), 성대접촉지수(Speed Qoutient) 및 진폭(pix$\mathrm{el})$ 이다. 결과: 허밍과 유성양순마찰음은 개방모음보다 $\mathrm{GQ}(p=.000)$ 와 $\mathrm{SQ}(p=.000)$ 가 유의하게 더 높았고, 진폭에서는 허밍 $(p=.018)$ 및 유성양순마찰음 $(p=.003)$ 이 개방모음보다 유의하게 작았다. 또한, 진동유형에 따라서는 이중진동원이 단일진동원에 비해 $\mathrm{GQ}$ $(p=.000)$ 와 SQ $(p=.008)$ 에서만 유의하게 높았다. 논의 및 결론: SOVTE는 개방모음과는 다르게 성문틈을 보이며 약간 외전된 형태의 성대진동을 보였으며, SOVTE 시 성대진동의 개방기가 더 길고 진폭은 더 작았다. 본 연구의 결과는 SOVTE를 이용한 음성치료와 음성 훈련에 대한 보다 과학적이고 직접적인 이론적, 임상적 근거를 제공한다는 점에서 의의를 가진다.

핵심어: 반폐쇄성도운동, 2D 디지털 카이모그래피, 진동시뮬레이터, 성대진동

본 연구는 대한민국 교육부와 한국연구재단의 지원을 받아수행된 연구임(NRF-2020S1A5A2a0145868).

\section{참고문헌}

김지성, 이동욱, 최철희, 최성희 (2017). 후두마사지와 반폐쇄성도훈련이 과기능적 음성장애 환자의 음성개선에 미치는 효과. Communication Sciences \& Disorders, 22(4), 806-817.

김지성, 최성희 (2021) 자가음성건강관리 프로그램을 이용한 비대면 음성치료의 효과. Communication Sciences \& Disorders, 26(2), 501-509.

김지성, 최성희, 최철희, 이동욱 (2019). 후두미세수술 이후 지속되는 발성장애의 음성치료 효과. Communication Sciences \& Disorders, 24(2), 525-

534.

김지성, 이동욱 (2020). 음성강화기법의 성대결절 치료 효과. 대한후두음성언어의학회지, 31(1), 13-18.

배인호 (2017). 진동 시뮬레이터를 이용한 평면 스캔 디지털 카이모그래피의 이중음성 감별효과. 부산대학교 대학원 박사학위논문.

박희준 (2015). 평면 스캔 비디오카이모그래피에서 영역 추출 알고리즘을 이용한 성대진동 평가 파라미터의 개발. 부산대학교 대학원 박사학위논문. 왕수건 (2013). 성대진동검사. 대한후두음성언어의학회지, 24(1), 28-32.

채혜림, 김지성, 이동욱, 최성희 (2019). 반폐쇄성도훈련이 기능적 실성증 환자의 음성 개선에 미치는 효과. 대한후두음성언어의학회지, 30(1), 48-52. 채혜림, 최성희, 최철희, 이경재 (2019). Lax Vox 음성치료가 파킨슨병 환자의 호흡 및 발성에 미치는 효과. Communication Sciences \& Disorders,

24(3), 785-799.

최철희, 최성희, 이경재 (2015). 말과학. 서울: 시그마프레스.

최홍식 (1998). 성도공명. 대한음성언어의학회 학술대회, 201-207. 


\section{ORCID}

김지성(제1저자, 언어재활사 https://orcid.org/0000-0003-2363-5060); 최성희(교신저자, 교수 https://orcid.org/0000-0003-2365-6187);

이경재(공동저자, 교수 https://orcid.org/0000-0002-6811-1212); 최철희(공동저자, 교수 https://orcid.org/0000-0003-1844-3072);

왕수건(공동저자, 교수 https://orcid.org/0000-0002-8059-0076); 이동욱(공동저자, 교수 https://orcid.org/0000-0002-3333-6083) 